\title{
Effects of Inspiratory Muscle Training in Older Adults
}

\author{
Mariana B Seixas, Leonardo B Almeida, Patrícia F Trevizan, Daniel G Martinez, \\ Mateus C Laterza, Luiz Carlos M Vanderlei, and Lilian P Silva
}

\begin{abstract}
BACKGROUND: Inspiratory muscle training (IMT) has been widely applied to different populations, including the general population of older adults. In addition to increasing inspiratory muscle strength, other benefits of IMT in the health of this population have been reported. The primary aim of this study was to review the effects of IMT on the general parameters of health (eg, respiratory, functional, physical, and other variables) in older adults $(\geq 60 \mathrm{y}$ ), and the secondary aim was to analyze the main IMT protocol used in the studies. METHODS: We searched the MEDLINE, PEDro, SciELO, and LILACS databases to identify relevant randomized controlled clinical trials, and we assessed their methodological quality according to the PEDro scale. The Preferred Reporting Items for Systematic review and Meta-Analysis (PRISMA) guidelines were used to guide the development of the protocol for this systematic review. RESULTS: The search yielded 7 studies involving 248 participants from 917 titles. The main outcomes investigated in response to IMT were related to the respiratory, functional, and physical variables. The results indicate that IMT promotes an increase of inspiratory muscle strength and diaphragmatic thickness in older adults. There was heterogeneity in the protocols described for this population with respect to the total training time (4-8 weeks), intensity (30-80\% of the maximum inspiratory pressure), and weekly frequency ( 5 or 7 sessions). CONCLUSIONS: The reviewed studies revealed a positive trend for the effectiveness of IMT in improving inspiratory muscle performance in elderly subjects. More randomized studies are needed to evaluate other outcomes (eg, functional capacity, exercise capacity, cardiac autonomic control, quality of life, and others) to provide robust evidence that this training modality can promote improvements in health parameters in this population. In addition, the usual IMT prescription in this population is based on sets and repetitions, of mild to moderate intensity, performed on most days of the week, for $\geq 4$ weeks. Key words: breathing exercises; exercise; aging; aged; muscle strength; respiratory muscle; physical therapy. [RespirCare 2020;65(4):535-544. (C) 2020 Daedalus Enterprises]
\end{abstract}

\section{Introduction}

Biological aging is characterized by the reduction of reparative and regenerative processes of tissues and or-

\footnotetext{
Ms Seixas is affiliated with the Faculty of Physiotherapy of the Federal University of Juiz de Fora (UFJF) and the Cardiovascular Research Unit and Exercise Physiology of the Faculty of Physical Education and Sports and University Hospital of the UFJF, Minas Gerais, Brazil. Mr Almeida and Dr Trevizan are affiliated with the Cardiovascular Research Unit and Exercise Physiology of the Faculty of Physical Education and Sports and University Hospital of the UFJF, Minas Gerais, Brazil. Drs Martinez and Laterza are affiliated with Faculty of Physical Education and Sports of the UFJF and the Cardiovascular Research Unit and Exercise Physiology of the Faculty of Physical Education and Sports and University Hospital of the UFJF, Minas Gerais, Brazil. Dr Vanderlei is affiliated with the São Paulo State University (UNESP) School of Technology and
}

gans, leading to the progressive decline of all organic functions and increased disease risk. ${ }^{1}$ Older adults undergo

\footnotetext{
Sciences, Presidente Prudente, São Paulo, Brazil. Dr Silva is affiliated with the Faculty of Physiotherapy of the UFJF and the Cardiovascular Research Unit and Exercise Physiology of the Faculty of Physical Education and Sports and Faculty of Physical Education and Sports and University Hospital of the UFJF, Minas Gerais, Brazil.
}

\footnotetext{
The authors are supported in part by the Coordenação de Aperfeiçoamento de Pessoal de Nível Superior-Brasil (CAPES) (finance code 001). The authors have disclosed no other conflicts of interest.
}

Correspondence: Mariana B Seixas MSc, Eugênio do Nascimento, s/n Dom Bosco, Juiz de Fora, Brazil, 36038-330. E-mail: mariana.balbi@ ufjf.edu.br.

DOI: $10.4187 /$ respcare. 06945 
loss of muscle mass (sarcopenia) and a decrease in strength of skeletal muscles (dynapenia), including respiratory muscles. $^{2-4}$ These changes related to senescence have an important clinical impact because the reduction of peripheral and respiratory muscle strength are associated with higher mortality in older adults. ${ }^{5,6}$

The regular practice of aerobic and resistance exercises, aside from balance and flexibility exercises, is recommended to maintain and promote the health of older adults. ${ }^{7}$ Some specific exercise modalities are proposed to improve respiratory muscle strength and allow a more mechanically efficient pattern of breathing. ${ }^{8}$ One of these modalities is inspiratory muscle training (IMT), which has been extensively studied.

IMT is performed by breathing against an external inspiratory load provided by different devices. It is easy to apply, represents a low-cost intervention, and is considered relevant in the rehabilitation scenario. ${ }^{9-11}$ This training has been applied in populations with different diseases, and it seems to be a promising tool for overall health improvement. ${ }^{12-14}$ In addition to increasing inspiratory muscle strength, ${ }^{15-17}$ prior literature has reported improvement in exercise capacity, ${ }^{15,18}$ functional autonomy, ${ }^{19}$ diaphragmatic thickness and mobility, ${ }^{17}$ and cardiac autonomic control ${ }^{20,21}$ in older adults.

Considering the benefits mentioned above, some authors have indicated IMT as an alternative or supplementary modality of training that can be used in older adults, especially when other types of exercises are not feasible. ${ }^{18,22}$ Therefore, the primary aim of this study was to review the isolated effects of IMT on the general parameters of health in older adults ( $\geq 60 \mathrm{y}$ ) independently of their health condition. Moreover, considering the wide variation in the prescription of this training modality, the secondary aim was to analyze the main IMT protocols used in older adults to contribute to the decision-making discussion in clinical practice.

\section{Methods}

The PRISMA guidelines were used to carry out this systematic review, and the research questions were structured according to the PICOS criteria. ${ }^{23,24}$ The search strategy in electronic databases (MEDLINE, PEDro, SciELO, and LILACS) was performed by associating the descriptors related to the population of interest (ie, "aged" or "elderly" or "older adults") with the intervention descriptors (ie, "breathing exercises" or "inspiratory muscle training" or "respiratory muscle training") from database inception to November 2018.

Randomized controlled trials (RCTs) written in either English or Portuguese were included. The studies included were carried out in older adults $(\geq 60 \mathrm{y})$ regardless of health condition who performed IMT (through inspiratory overload devices) to assess its isolated effects on health parameters. IMT was compared to sham inspiratory training, control group, and other types of intervention. Studies that used IMT in association with other respiratory physiotherapy techniques, expiratory muscle training, or aerobic/resistive physical training were excluded. Similarly, in alignment with the secondary aim of this review, studies that did not describe the training protocol in detail (ie, number of sets and repetitions, time of training, weekly frequency, intensity, and type of device used) were also excluded.

The search and selection of articles were performed by 2 independent reviewers (MBS, LBA), and any disagreements during the process were decided by consensus. Articles were first selected if their title was relevant to the scope of this review. Subsequently, abstracts were read to verify whether they met the established inclusion criteria. We searched for additional articles in the reference lists of the selected studies. The selected articles were read in full to extract the data of interest for this review. The final evaluation of each article included in this review was done with the PEDro scale, which is based on the Delphi list; it has 11 criteria and aims to assess the quality of RCTs that are relevant evidence in physiotherapy. Articles evaluated with the PEDro scale may have scores ranging from 1 to 10. A score of $9-10$ was classified as excellent, a score of 6-8 was good, a score of 4-5 was fair, and a score of $<4$ was poor. ${ }^{25,26}$ The reviewers independently rated the papers, and any disagreements were resolved by consensus. A systematic narrative synthesis was used to present the results of the review in the form of text and tables.

\section{Results}

In the initial search were identified 917 articles, of which 7 were deemed eligible for this systematic review after the screening process and eligibility analysis (Fig. 1). These studies investigated the effect of IMT on the intervention group in comparison to (1) a control group with no intervention, $22,27,28$ (2) a group that performed the same protocol as the intervention group but without a resistive load, ${ }^{16,17}$ or (3) a group that performed the same protocol as the intervention group but with the minimum resistive load offered by the device used..$^{15,21}$ Two studies also included a third comparison, in which the participants performed yoga breathing exercises ${ }^{27}$ or incentive spirometry. ${ }^{28}$ These studies investigated the effects of IMT on frail, institutionalized, older adults with significant activity limitation and respiratory muscle weakness, ${ }^{27}$ older women institutionalized with functional limitation and accentuated respiratory muscle weakness, ${ }^{22}$ older women able to walk independently and without spirometric or cognitive alterations, ${ }^{17}$ healthy older adults, ${ }^{16,21,28}$ and moderately active healthy 


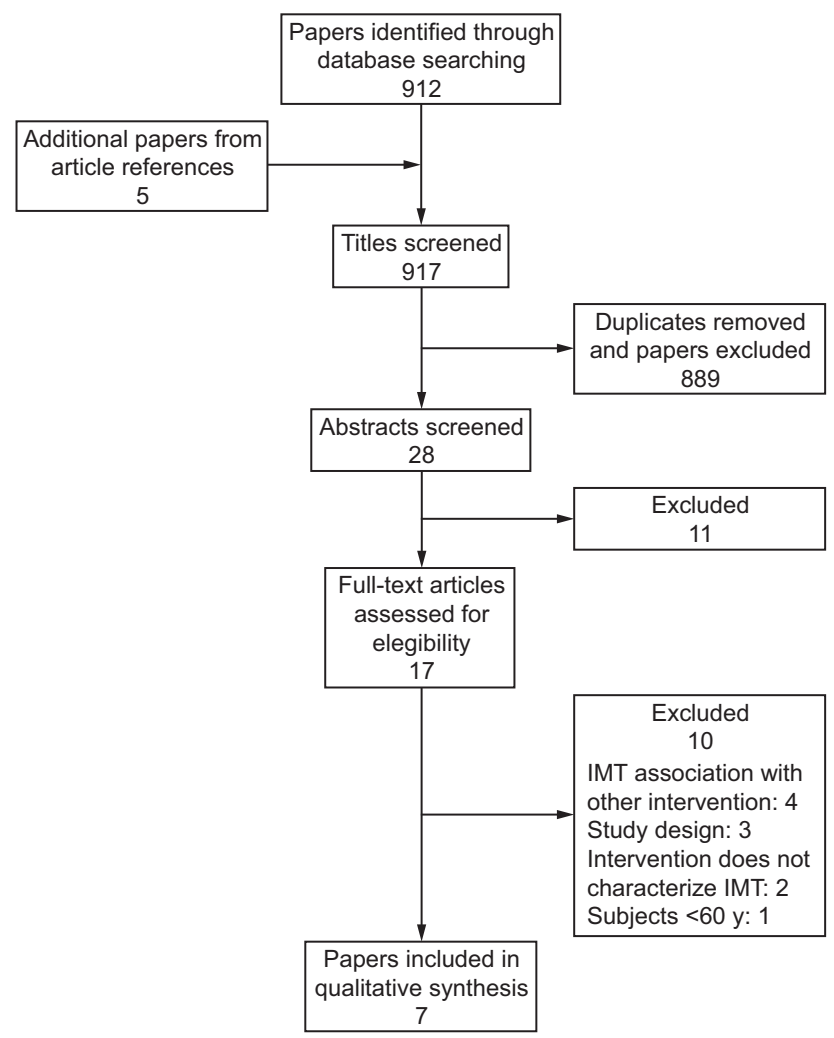

Fig. 1. Flow chart. IMT = inspiratory muscle training.

older adults. ${ }^{15}$ The total sample included 248 subjects, with a mean age of 64-88 y (Table 1).

The articles were evaluated for methodological quality (Table 2) and ranged from 5 to 8 points (fair or good quality). All articles met the eligibility criteria (criterion number one is not scored), randomly allocated the participants to the groups, described the results of betweengroup statistical comparisons, and presented measurements of point and variability for at least one of the key outcomes. In $29 \%$ of the articles, the subjects' allocation was concealed; in $43 \%$ of the articles, there was blinding of older adults who participated in the study. Moreover, in $71 \%$ of the included articles, the groups were initially similar at baseline to the most important prognostic indicators, and in $57 \%$ the assessors blindly measured at least 1 key outcome. Measurements of at least 1 key outcome were obtained in $>85 \%$ of the subjects initially allocated to groups in $71 \%$ of the articles. There was, however, no blinding of therapists who administered the therapy in any of the articles included, nor was there any description of whether all participants received the treatment or the control condition as allocation or if the data were analyzed by "intention to treat."

The outcomes related to the respiratory system evaluated in the studies were respiratory muscle strength, respiratory muscle endurance, diaphragm muscle thickness and mobility, and measures of chest wall expansion and lung function.

Respiratory muscle strength was assessed in all of the studies using the maximum inspiratory pressure $\left(\mathrm{P}_{\text {Imax }}\right)$ or maximum expiratory pressure $\left(\mathrm{P}_{\text {Emax }}\right)$ measurement. The inspiratory muscle strength was a primary outcome in all studies, and the expiratory muscle strength was analyzed in 5 studies. ${ }^{16,17,22,27,28}$ Most of the studies (86\%) showed that IMT promoted an increase in subjects' $P_{\text {Imax }} \cdot{ }^{15-17,21,22,28}$ However, Cebrià i Iranzo et $\mathrm{al}^{27}$ did not find significant changes in this outcome after intervention, observing an increase in $\mathrm{P}_{\text {Imax }}$ only after training with yoga breathing exercises. On the other hand, the $\mathrm{P}_{\mathrm{Emax}}$ significantly increased after IMT in 2 studies. ${ }^{17,22}$ Similarly, Cebrià i Iranzo et al ${ }^{27}$ observed an increase in this variable after the intervention with yoga breathing exercises.

Three studies ${ }^{16,22,27}$ evaluated respiratory muscle endurance through the maximum voluntary ventilation, but only one verified significant change after IMT. ${ }^{22}$ In this study, there was an increase in the maximum voluntary ventilation after 3 weeks from the end of the training (follow-up) in comparison to the baseline values.

Diaphragm muscle thickness increased in response to IMT in 2 studies using a noninvasive technique of ultrasonography. ${ }^{16,17}$ Furthermore, Souza et al ${ }^{17}$ also observed improvement in diaphragm mobility after this intervention.

Only one study selected for this review measured chest wall expansion, and it did not verify any changes in this variable after 4 weeks of IMT. However, the group that underwent incentive spirometry showed increased lower chest wall expansion. ${ }^{28}$

The lung function variables assessed with spirometry were analyzed in 3 studies. ${ }^{16,21,28}$ Mills et al ${ }^{16}$ observed increase in peak inspiratory flow after the intervention, and Reychler et $\mathrm{al}^{28}$ reported a significant increase in FVC and $\mathrm{FEV}_{1}$ in the 3 groups evaluated. On the other hand, Rodrigues et $\mathrm{al}^{21}$ did not observe changes in the parameters assessed.

Mills et $\mathrm{al}^{16}$ and Rodrigues et $\mathrm{al}^{21}$ used the 6-min walk test to investigate the effect of IMT on the functional capacity of older adults. In the first study, no significant changes were found in the distance achieved in the test by both the IMT group and the sham group. However, an increase in heart rate immediately after the test in the sham group occurred post-intervention. On the other hand, the second study showed a significant improvement in the test performance and recovery heart rate in the IMT group.

The exercise capacity was evaluated by Aznar-Lain et al ${ }^{15}$ through the exercise test and determination of peak oxygen uptake (peak $\dot{\mathrm{V}}_{\mathrm{O}_{2}}$ ). In this study, IMT promoted an increase in peak $\dot{\mathrm{V}}_{\mathrm{O}_{2}}$ and time to exhaustion during the fixed load test in the group that received the intervention, which represents an improvement in endurance in response 


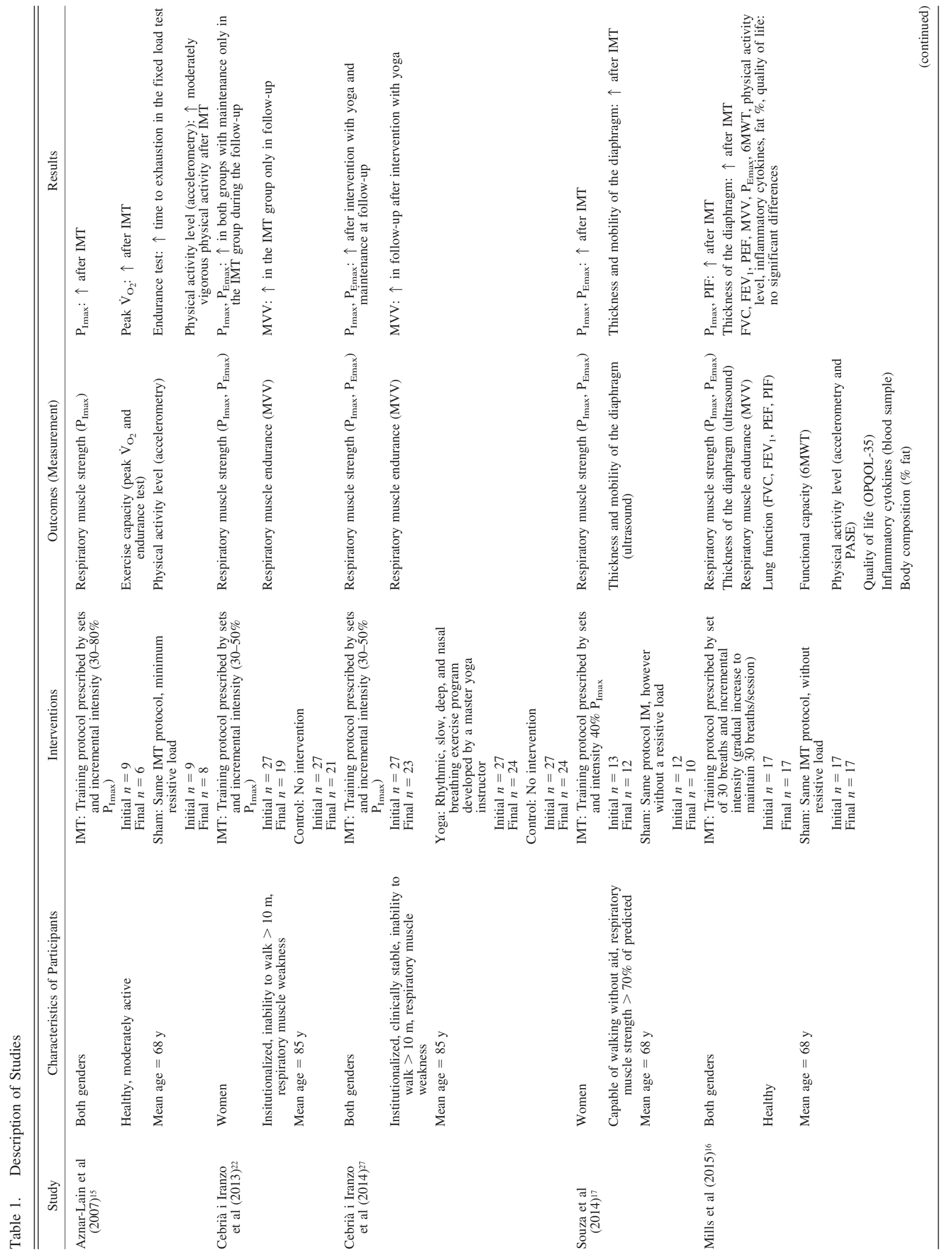


InSPIRAtory Muscle Training IN Older Adults

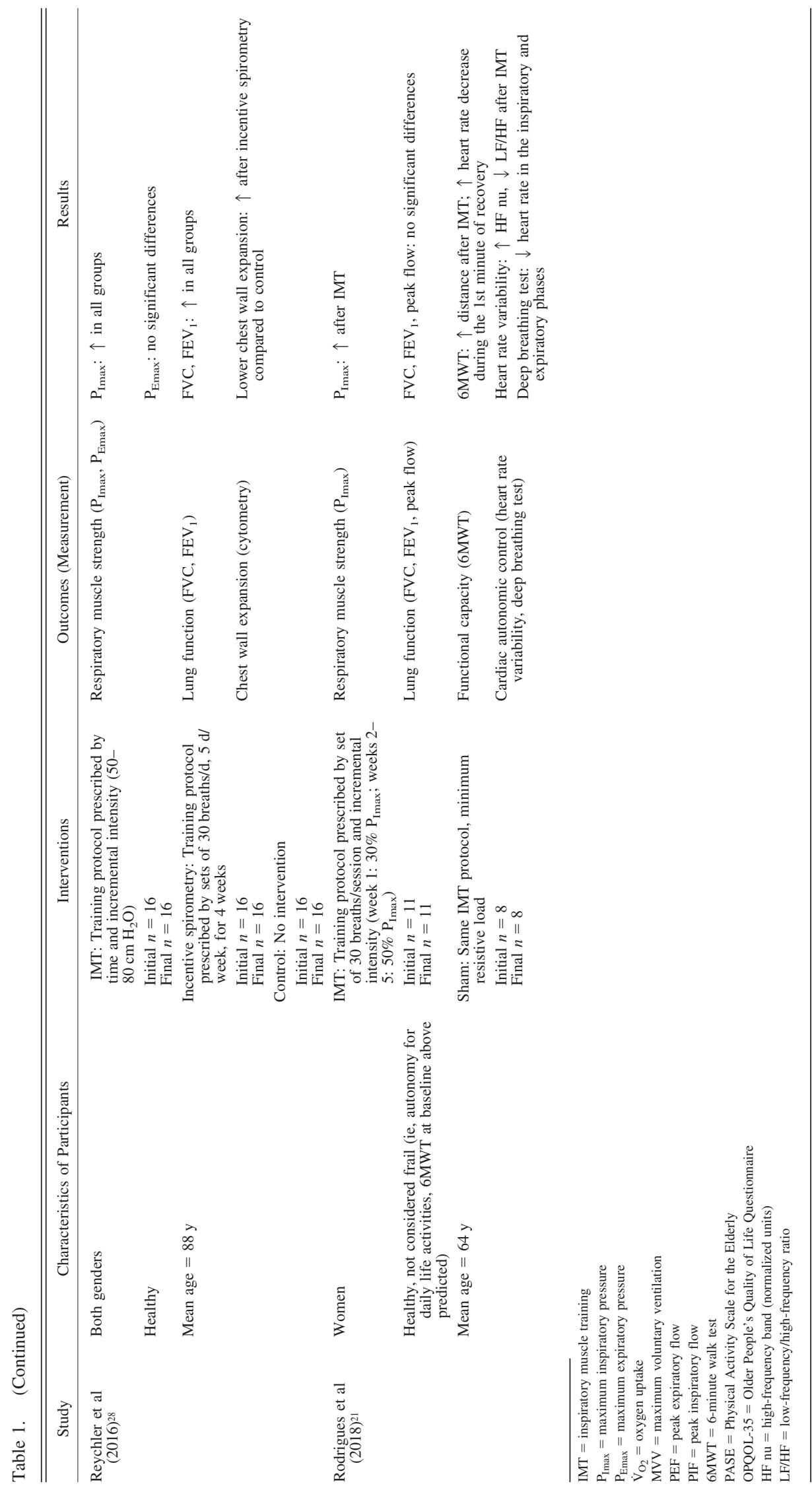


Table 2. Quality of the Studies Evaluated*

\begin{tabular}{|c|c|c|c|c|c|c|c|}
\hline Criteria & $\begin{array}{l}\text { Aznar-Lain et al } \\
\qquad(2007)^{15}\end{array}$ & $\begin{array}{l}\text { Cebrià i Iranzo } \\
\text { et al }(2013)^{22}\end{array}$ & $\begin{array}{l}\text { Cebrià i Iranzo } \\
\text { et al (2014) }\end{array}$ & $\begin{array}{l}\text { Souza et al } \\
(2014)^{17}\end{array}$ & $\begin{array}{l}\text { Mills et al } \\
(2015)^{16}\end{array}$ & $\begin{array}{l}\text { Reychler } \\
\text { et al } \\
(2016)^{28}\end{array}$ & $\begin{array}{l}\text { Rodrigues et al } \\
\qquad(2018)^{21}\end{array}$ \\
\hline Random allocation & Yes & Yes & Yes & Yes & Yes & Yes & Yes \\
\hline Concealed allocation & No & No & Yes & Yes & No & No & No \\
\hline Baseline comparability & No & Yes & Yes & Yes & No & Yes & Yes \\
\hline Participants blinded & Yes & No & No & Yes & Yes & No & Yes \\
\hline Therapists blinded & No & No & No & No & No & No & No \\
\hline Blind assessors & Yes & Yes & Yes & Yes & No & No & No \\
\hline Follow-up & Yes & No & Yes & Yes & Yes & Yes & No \\
\hline Intention to treat analysis & No & No & No & No & No & No & No \\
\hline Group comparisons & Yes & Yes & Yes & Yes & Yes & Yes & Yes \\
\hline Point and variability measures & Yes & Yes & Yes & Yes & Yes & Yes & Yes \\
\hline Total score & 6 & 5 & 7 & 8 & 5 & 5 & 5 \\
\hline
\end{tabular}

to the training. These authors also observed an increase in moderate-to-vigorous physical activity after IMT.

In addition to outcomes related to the respiratory system and physical and functional variables, Rodrigues et $\mathrm{al}^{21}$ evaluated the effects of IMT on cardiac autonomic control and observed an improvement in heart rate variability after this intervention with increase in the high-frequency power of the heart rate variability and, consequently, decrease in the low-frequency/high-frequency ratio.

Mills et $\mathrm{al}^{16}$ also evaluated the effect of IMT on quality of life, plasma cytokine concentrations, and body composition, and the authors did not observe significant changes in these variables in older adults after the training.

Table 3 describes the IMT protocols of the studies included in this review. All studies used pressure linear load devices for IMT, and most opted for Threshold (Threshold Inspiratory Muscle Trainer, Philips, Murraysville, PA). ${ }^{15,17,22,27,28}$ The total training time ranged from 4-8 weeks with weekly frequency of 5 sessions ${ }^{15,21,22,27,28}$ or 7 sessions. ${ }^{16,17}$ The training intensity used in the protocols ranged from $30 \%$ to $80 \%$ of the $\mathrm{P}_{\text {Imax }}$. Load adjustments were reported after further measurements of maximum inspiratory muscle strength. In one study, the intensity was not determined as a percentage of $\mathrm{P}_{\text {Imax }}$ but was pre-fixed at $50 \mathrm{~cm} \mathrm{H}_{2} \mathrm{O}$ and increased by $10 \mathrm{~cm} \mathrm{H}_{2} \mathrm{O}$ each week. ${ }^{28}$

One of the papers used the prescription based on time, ${ }^{28}$ while all of the others adopted the prescription based on sets and repetitions. ${ }^{15-17,21,22,27}$ Four studies reported that training sessions were supervised by a therapist. ${ }^{15,22,27,28}$ One paper reported supervised sessions only once a week, ${ }^{17}$ another protocol decided for supervision twice throughout the training program (at 2 weeks and 4 weeks after initiation of the protocol), ${ }^{16}$ and the last study reported that the sessions were performed at home and did not provide supervision information. ${ }^{21}$

\section{Discussion}

To our knowledge, this review is the first to systematically review the effects of IMT in older adults. In view of the small number of RCTs found, besides the heterogeneity of them, the grouping of effects between the studies in the meta-analysis was not considered adequate at this stage in this review. As expected, the most frequently investigated outcome was inspiratory muscle strength. Although there is a great heterogeneity in the characteristics of the subjects included in the selected studies, our findings indicate that IMT contributes to increasing the inspiratory muscle strength in older adults.

As with all skeletal muscles, respiratory muscles can improve their function in response to physical training in view of the universal principles of overload, specificity, individuality, and reversibility. ${ }^{29}$ The absence of improvement in inspiratory muscle strength in response to the training verified in one of the studies, ${ }^{27}$ as well as a similarly observed increase in the control and IMT groups in 2 studies, ${ }^{22,28}$ may be related to the sample characteristics or to the training protocol. In these 3 studies, the mean age of participants was higher in comparison to other studies included in this review $(88,88$, and $85 \mathrm{y}$ vs 68 and $64 \mathrm{y}$, respectively). Moreover, the study by Reychler et al ${ }^{28}$ was the only one to use a prescription by time $(15 \mathrm{~min} / \mathrm{d})$, and the intensity was not determined as a percentage of the $\mathrm{P}_{\text {Imax }}$. Cebrià i Iranzo et $\mathrm{al}^{27}$ also cited the low training load during the first 4 weeks and the short protocol time (ie, 6 weeks) as potential reasons for the absence of increased strength in institutionalized older adults. Accord- 
Table 3. Description of Inspiratory Muscle Training Protocol

\begin{tabular}{|c|c|c|c|c|c|c|}
\hline Study & Prescription & $\begin{array}{l}\text { Weekly Frequency and } \\
\text { Progression }\end{array}$ & $\begin{array}{l}\text { Intensity and Progression } \\
\text { of Load }\end{array}$ & Load Readjustment & Duration & Training Device \\
\hline \multirow[t]{4}{*}{$\begin{array}{l}\text { Aznar-Lain et al } \\
(2007)^{15}\end{array}$} & $\begin{array}{l}\text { Week } 1: 8 \text { sets of } 5 \text { repetitions } \\
\quad(1 \text { min rest between sets })\end{array}$ & \multirow[t]{4}{*}{$\begin{array}{l}\text { Week 1: } 3 \text { times/week } \\
\text { Week 2-8: } 5 \text { times/week }\end{array}$} & Weeks 1-2: $50 \% \mathrm{P}_{\text {Imax }}$ & \multirow[t]{4}{*}{$\begin{array}{l}\text { Beginning of the week } 5 \\
\text { by evaluating } \mathrm{P}_{\mathrm{Imax}}\end{array}$} & \multirow[t]{4}{*}{8 weeks } & \multirow[t]{4}{*}{ Threshold } \\
\hline & $\begin{array}{l}\text { Weel 2: } 9 \text { sets of } 5 \text { repetitions } \\
(1 \text { min rest between sets) }\end{array}$ & & Week 3: $60 \% \mathrm{P}_{\text {Imax }}$ & & & \\
\hline & $\begin{array}{l}\text { Week 3: } 10 \text { sets of repetitions } \\
\quad(1 \text { min rest between sets })\end{array}$ & & Week 4: $70 \% P_{\text {Imax }}$ & & & \\
\hline & $\begin{array}{l}\text { Weeks } 4-8: 10 \text { sets of } \\
6 \text { repetitions ( } 1 \text { min rest } \\
\text { between sets) }\end{array}$ & & Weeks 5-8: $80 \% \mathrm{P}_{\text {Imax }}$ & & & \\
\hline \multirow[t]{2}{*}{$\begin{array}{l}\text { Cebrià i Iranzo et } \\
\text { al (2013)22 }\end{array}$} & $\begin{array}{l}7 \text { sets of } 2 \text { min of exercise } \\
\text { ( } 1 \text { min rest between sets) }\end{array}$ & \multirow[t]{2}{*}{5 times/week } & \multirow{2}{*}{$\begin{array}{l}30-50 \% \mathrm{P}_{\text {Imaxa }} ; \text { incremental } \\
\text { increase of workload } \\
\text { according to participant } \\
\text { tolerance }\end{array}$} & \multirow[t]{2}{*}{$\begin{array}{l}\text { Beginning of the week } 4 \\
\text { by evaluating } P_{\text {Imax }}\end{array}$} & \multirow[t]{2}{*}{6 weeks } & \multirow[t]{2}{*}{ Threshold } \\
\hline & $\begin{array}{l}\text { Week 1: low workloads } \\
\left(7-10 \mathrm{~cm} \mathrm{H}_{2} \mathrm{O}\right) \text { for } \\
\text { familiarization }\end{array}$ & & & & & \\
\hline \multirow[t]{2}{*}{$\begin{array}{l}\text { Cebrià i Iranzo et } \\
\text { al (2014)27 }\end{array}$} & 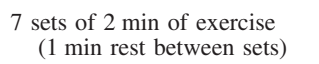 & \multirow[t]{2}{*}{5 times/week } & \multirow{2}{*}{$\begin{array}{l}\text { 30-50\% } \mathrm{P}_{\text {Imax }} \text {; incremental } \\
\text { increase of workload } \\
\text { every } 2 \mathrm{~d} \text { according to } \\
\text { participant tolerance }\end{array}$} & \multirow[t]{2}{*}{$\begin{array}{l}\text { Beginning of week } 4 \text { by } \\
\text { evaluating } P_{\text {Imax }}\end{array}$} & \multirow[t]{2}{*}{6 weeks } & \multirow[t]{2}{*}{ Threshold } \\
\hline & $\begin{array}{l}\text { Week 1: 2-d familiarization } \\
\text { period at the beginning of } \\
\text { the protocol }\end{array}$ & & & & & \\
\hline $\begin{array}{l}\text { Souza et al } \\
(2014)^{17}\end{array}$ & $\begin{array}{l}8 \text { sets of } 2 \text { min of exercise } \\
(1 \text { min rest per series })\end{array}$ & 7 days/week (2 times/d) & $40 \% \mathrm{P}_{\operatorname{Imax}}$ & $\begin{array}{l}\text { Weekly by evaluating } \\
\mathrm{P}_{\text {Imax }}\end{array}$ & 8 weeks & Threshold \\
\hline Mills et al (2015)16 & 30 breaths/session & 7 days/week (2 times/d) & $\begin{array}{l}\text { Initial intensity } 50 \% \mathrm{P}_{\text {Imax }} \\
\text { gradual increase to } \\
\text { reach } 30 \text { breaths/session }\end{array}$ & $\begin{array}{l}\text { Periodic increase of load } \\
\text { so only } 30 \text { maneuvers } \\
\text { are completed }\end{array}$ & 8 weeks & POWERbreathe \\
\hline \multirow{4}{*}{$\begin{array}{l}\text { Reychler et al } \\
\quad(2016)^{28}\end{array}$} & \multirow[t]{4}{*}{15 min (15-20 breaths/min) } & \multirow[t]{4}{*}{5 times/week } & Week 1: $50 \mathrm{~cm} \mathrm{H}_{2} \mathrm{O}$ & \multirow[t]{4}{*}{ NA } & \multirow[t]{4}{*}{4 weeks } & \multirow[t]{4}{*}{ Threshold } \\
\hline & & & Week 2: $60 \mathrm{~cm} \mathrm{H}_{2} \mathrm{O}$ & & & \\
\hline & & & Week 3: $70 \mathrm{~cm} \mathrm{H}_{2} \mathrm{O}$ & & & \\
\hline & & & Week 4: $80 \mathrm{~cm} \mathrm{H}_{2} \mathrm{O}$ & & & \\
\hline \multirow[t]{2}{*}{$\begin{array}{l}\text { Rodrigues et al } \\
(2018)^{21}\end{array}$} & \multirow[t]{2}{*}{30 breaths/session } & \multirow[t]{2}{*}{5 days/week (2 times/d) } & $\begin{array}{l}\text { Week 1: } 30 \% \mathrm{P}_{\operatorname{Imax}} \\
\quad \text { (familiarization) }\end{array}$ & \multirow[t]{2}{*}{$\begin{array}{l}\text { Weekly by evaluating } \\
\mathrm{P}_{\text {Imax }}\end{array}$} & \multirow[t]{2}{*}{5 weeks } & \multirow[t]{2}{*}{ POWERbreathe } \\
\hline & & & Weeks 2-5: 50\% $\mathrm{P}_{\text {Imax }}$ & & & \\
\hline
\end{tabular}

$\overline{\mathrm{P}_{\operatorname{Imax}}=\text { maximum inspiratory pressure }}$

ing to the results of this review, it was possible to note 2 groups: healthy older adults ${ }^{15-17,21,28}$ and institutionalized older adults with functional impairment. ${ }^{22,27}$ Considering that the inspiratory muscle strength was the only variable assessed in all of the selected studies, it is possible to compare this outcome between these groups. Whereas IMT promoted increase of $\mathrm{P}_{\text {Imax }}$ in healthy older adults, its effects were contradictory in the studies with institutionalized older adults. A possible explanation for this unexpected result is that the protocol applied (ie, intensity or duration) may have been insufficient to promote respiratory strength improvement in this older adult population with functional impairment.

In addition, it is important to highlight that Cebrià $\mathrm{i}$ Iranzo et $\mathrm{al}^{27}$ reported an increase in inspiratory and expiratory muscle strength in response to training with yoga. This finding may be related to improvement in the recruitment of motor units and in the muscle length-tension relationship promoted by the yoga breathing exercises, which could provide greater power to the $\mathrm{P}_{\mathrm{Emax}}$ and $\mathrm{P}_{\text {Imax }}$ maneuvers. ${ }^{27,30,31}$

Although this training modality aimed primarily to improve inspiratory muscle strength, some studies also verified an increase of expiratory muscle strength. ${ }^{17,22}$ This effect can be partially explained by neural adaptation fac- tors. The exposure to repeated stimuli of strength, which is a learning effect, may contribute to improving the muscle recruitment pattern and increased strength. ${ }^{17,30}$ Another possible explanation is the increase in inspiratory muscles strength in response to this training modality, given that the expiratory effort can be maximized in high volumes generated by the stronger action of the diaphragm. ${ }^{31}$

Reduced respiratory strength has been identified as a predictor of poor prognosis ${ }^{32}$ and mortality ${ }^{33}$ in some diseases. In older adults, there is an association between reduced respiratory muscle strength and poor physical performance, ${ }^{34,35}$ and $\mathrm{P}_{\mathrm{Imax}}$ is considered an independent risk factor for myocardial infarction and cardiovascular disease death. ${ }^{36}$ In addition, Buchman et $\mathrm{l}^{6}$ concluded that respiratory muscle strength may explain the association between peripheral muscle strength and mortality. According to the authors, the respiratory muscle strength may be at the beginning of a causal chain that would lead to decreased lung function and death; thus, interventions that increase this outcome have an important positive clinical impact in this population. ${ }^{6}$

The respiratory endurance assessed by maximum voluntary ventilation showed an increase after 3 weeks of IMT in one of the studies. ${ }^{22}$ Other studies that evaluated this variable did not show significant effects. ${ }^{16,27}$ In this 
regard, although respiratory muscle training is often treated as a single training modality, it can be understood as 2 distinct types: respiratory muscle strength training and respiratory muscle endurance training. ${ }^{9}$ The first is the training addressed in this review (ie, IMT), which consists of performing breaths against an inspiratory pressure load, being characterized by high-intensity and low-speed contractions, and aiming specifically to increase the muscle strength. On the other hand, endurance training is performed through the normocapnic hyperpnea technique, which consists of hyperventilation under conditions of normocapnia, aiming to reach a predetermined volume per minute, at which point the inspiratory and expiratory muscle contractions occur with a lower intensity but at a higher speed, resulting in a specific respiratory endurance improvement. . $^{9,37}$ Therefore, an improvement in respiratory endurance was not expected because the studies used a technique for strength improvement.

The thickness of the diaphragm increased after IMT in the 2 studies included in this review that assessed this parameter. Because the inspiratory muscles are morphologically and functionally skeletal muscles, they must respond as any locomotor muscle when an overload stimulus is applied. ${ }^{88,39}$ In fact, other studies have reported an increase in this parameter after high-intensity IMT in moderately trained healthy adults ${ }^{40}$ and in subjects with cystic fibrosis. ${ }^{41}$ The results shown in this review suggest an association between increased inspiratory muscle strength and muscular hypertrophy. ${ }^{16,17}$ It is noteworthy that the subjects in these studies were apparently healthy older adults, which limits the generalization to older adults with other characteristics, especially those with significant respiratory muscle weakness.

In adults with cardiac or pulmonary disease, it seems that IMT may contribute to improving pulmonary function measurements, such as in heart failure, ${ }^{42}$ atrial fibrillation $^{43}$ and post-cardiac surgery. ${ }^{44}$ In this systematic review, the absence of changes in lung function may be related to the fact that studies that assessed this outcome were conducted with apparently healthy older adults.

The functional capacity improvement after IMT has been documented in subjects with heart failure ${ }^{14}$ and sarcoidosis. ${ }^{45}$ Similarly, this training modality has been used in healthy individuals, mainly in those with lower physical fitness and in athletes to improve physical performance. ${ }^{9}$ These effects are partially correlated to the attenuation of the respiratory metaboreflex promoted by IMT. ${ }^{46}$ However, although functional capacity has important clinical importance, it was only assessed in 2 studies included in this review, and one of them observed no change in the 6-min walk test, attributing it to the high functional capacity of the participants at baseline. ${ }^{16}$ Thus, individuals who have lower functional capacity may be the ones who benefit the most from the intervention..$^{9,16}$ On the other hand, Rodrigues et al ${ }^{21}$ reported an increase of the distance achieved in the 6-min walk test after the intervention, and Aznar-Lain et al ${ }^{15}$ reported improvement in the peak $\dot{\mathrm{V}}_{\mathrm{O}_{2}}$ and time of the fixed load test after IMT. Therefore, although it seems that this intervention can contribute to improve the exercise and functional capacity of older adults, further studies should be conducted.

Only one study included in this review evaluated the effect of IMT on heart rate variability and observed improvement on cardiac autonomic control. ${ }^{21}$ Similarly, 2 recent systematic reviews concluded that this modality of training may promote benefits for cardiac autonomic control in subjects with risk factors for cardiovascular diseases ${ }^{47}$ and in subjects with other diseases. ${ }^{48}$ Furthermore, only Mills et al ${ }^{16}$ evaluated the effect of IMT on other outcomes, such as quality of life, inflammatory cytokines plasma levels, and body composition in older adults, which limits the discussion of these results.

An important aim of this review was to discuss the main IMT protocol used in older adults. There does not appear to be any standardization regarding IMT prescription, and there is a wide variety of protocols described in the literature. Therefore, most of the studies used protocols prescribed by sets and repetitions, from mild to moderate intensity, 5-7 times per week, for at least 4 weeks. Although the intensity, weekly frequency, and total training time were similar to those commonly reported in other populations, IMT prescription based on sets and repetitions was rare. Most of the studies presented in systematic reviews regarding the effects of IMT on patients with heart failure, ${ }^{42,49} \mathrm{COPD},{ }^{50}$ and stroke, ${ }^{51}$ for instance, use time as a prescription parameter (eg, 15-30 min). However, the reason for the choice of protocols used in those studies was not mentioned, nor was is discussed in the studies selected for this review.

All included studies were RCTs, and none were rated as poor in methodological quality according to the PEDro score, which suggests that the data presented are reliable. However, these results should be interpreted with caution because substantial heterogeneity was present among the included studies. In addition, none of the studies blinded the therapists who administered the interventions. Often it is not possible to blind participants or therapists to physical activity interventions. However, this is possible when simulated treatment is done in one of the groups, and this situation occurred in 4 studies (57\%). Another important finding is that only $29 \%$ of the studies concealed the allocation, and this information is not clear in most of the studies included in this review. According to the PEDro scale explanation, it is empirical evidence that concealment predicts effect size. Although the risk of bias assessment by the PEDro scale has some limitation, it has been validated and is widely used in the literature. 
Moreover, the conclusions of some effects of IMT are limited by the small number of eligible studies, mainly regarding other effects of this training modality. Thus, we emphasize the importance of more clinical RCTs on this relevant theme.

\section{Conclusions}

This review reveals that IMT can contribute to an increase in inspiratory muscle strength and diaphragm thickness in older adults (ie, $\geq 60 \mathrm{y}$ old). Moreover, it seems that this training modality can contribute to improve exercise and functional capacity, physical activity level, and cardiac autonomic control. Despite the heterogeneity of protocols prescribed for this population, IMT prescriptions based on sets and repetitions, from mild to moderate intensity, 5-7 times per week, for at least 4 weeks were more frequently used in the studies.

\section{REFERENCES}

1. Khan SS, Singer BD, Vaughan DE. Molecular and physiological manifestations and measurement of aging in humans. Aging Cell 2017;16(4):624-633.

2. Enright PL, Kronmal RA, Manolio TA, Schenker MB, Hyatt RE. Respiratory muscle strength in the elderly. Correlates and reference values. Cardiovascular Health Study Research Group. Am J Respir Crit Care Med 1994;149(2):430-438.

3. Manini TM, Clark BC. Dynapenia and aging: an update. J Gerontol A Biol Sci Med Sci 2012;67(1):28-40.

4. Shin HI, Kim DK, Seo KM, Kang SH, Lee SY, Son S. Relation between respiratory muscle strength and skeletal muscle mass and hand grip strength in the healthy elderly. Ann Rehabil Med 2017; 41(4):686-692.

5. Al Snih S, Markides KS, Ray L, Ostir GV, Goodwin JS. Handgrip strength and mortality in older Mexican Americans. J Am Geriatr Soc 2002;50(7):1250-1256.

6. Buchman AS, Boyle PA, Wilson RS, Gu L, Bienias JL, Bennett DA. Pulmonary function, muscle strength and mortality in old age. Mech Ageing Dev 2008;129(11):625-631.

7. Nelson ME, Rejeski WJ, Blair SN, Duncan PW, Judge JO, King AC, et al. Physical activity and public health in older adults: recommendation from the American College of Sports Medicine and the American Heart Association. Circulation 2007;116(9):1094-1105.

8. Shephard RJ. Aging, respiratory function, and exercise. J Aging Phys Act 1993;1(1):59-83.

9. Illi SK, Held U, Frank I, Spengler CM. Effect of respiratory muscle training on exercise performance in healthy individuals. Sports Med 2012;42(8):707-724.

10. Shei RJ, Paris HL, Wilhite DP, Chapman RF, Mickleborough TD. The role of inspiratory muscle training in the management asthma and exercise-induced bronchoconstriction. Phys Sportsmed 2016; 44(4):327-334.

11. Dellweg D, Reissig K, Hoehn E, Siemon K, Haidl P. Inspiratory muscle training during rehabilitation in successfully weaned hypercapnic patients with COPD. Respir Med 2017;123:116-123.

12. Ferreira JB, Plentz RD, Stein C, Casali KR, Arena R, Lado PD. Inspiratory muscle training reduces blood pressure and sympathetic activity in hypertensive patients: a randomized controlled trial. Int J Cardiol 2013;166(1):61-67.
13. Kaminski DM, Schaan BD, Silva AM, Soares PP, Lago PD. Inspiratory muscle training in patients with diabetic autonomic neuropathy: a randomized clinical trial. Clin Auton Res 2015;25(4):263-266.

14. Plentz RD, Sbruzzi G, Ribeiro RA, Ferreira JB, Dal Lago P. Inspiratory muscle training in patients with heart failure: meta-analysis of randomized trials. Arq Bras Cardiol 2012;99(2):762-771.

15. Aznar-Lain S, Webster AL, Canete S, San Juan AF, López Mojares LM, Pérez M, et al. Effects of inspiratory muscle training on exercise capacity and spontaneous physical activity in elderly subjects: a randomized controlled pilot trial. Int J Sports Med 2007;28(12): 1025-1029.

16. Mills DE, Johnson MA, Barnett YA, Smith WH, Sharpe GR. The effects of inspiratory muscle training in older adults. Med Sci Sports Exerc 2015;47(4):691-697.

17. Souza H, Rocha T, Pessoa M, Rattes C, Brandão D, Fregonezi G, et al. Effects of inspiratory muscle training in elderly women on respiratory muscle strength, diaphragm thickness and mobility. J Gerontol A Biol Sci Med Sci 2014;69(12):1545-1553.

18. Watsford M, Murphy A. The effects of respiratory-muscle training on exercise in older women. J Aging Phys Act 2008;16(3):245-260.

19. Fonseca MA, Cader AS, Dantas EH, Bacelar SC, Silva EB, Leal SM. Programas de treinamento muscular respiratório: impacto na autonomia funcional de idosos. Rev Assoc Med Bras 2010;56(6):642648.

20. Feriani DJ, Coelho HJ, Scapini KB, de Moraes OA, Mostarda C, Ruberti OM, et al. Effects of inspiratory muscle exercise in the pulmonary function, autonomic modulation, and hemodynamic variables in older women with metabolic syndrome. J Exerc Rehabil 2017;13(2):218-226.

21. Rodrigues GD, Gurgel JL, Gonçalves TR, da Silva Soares PP. Inspiratory muscle training improves physical performance and cardiac autonomic modulation in older women. Eur J Appl Physiol 2018; 118(6):1143-1152.

22. Cebria i Iranzo MD, Arnall DA, Igual Camacho C, Tomas JM, Melendez JC. Physiotherapy intervention for preventing the respiratory muscle deterioration in institutionalized older women with functional impairment. Arch Bronconeumol 2013;49(1):1-9.

23. Shamseer L, Moher D, Clarke M, Ghersi D, Liberati A, Petticrew M, et al. Preferred reporting items for systematic review and metaanalysis protocols (PRISMA-P) 2015: elaboration and explanation. BMJ 2015;350:g7647.

24. Harris JD, Quatman CE, Manring MM, Siston RA, Flanigan DC. How to write a systematic review. Am J Sports Med 2014;42(11): 2761-2768.

25. Fernández-Argüelles EL, Rodríguez-Mansilla J, Antunez LE, Garrido-Ardila EM, Muñoz RP. Effects of dancing on the risk of falling related factors of healthy older adults: a systematic review. Arch Gerontol Geriatr 2015;60(1):1-8.

26. Roberts CE, Phillips LH, Cooper CL, Gray S, Allan JL. Effect of different types of physical activity on activities of daily living in older adults: systematic review and meta-analysis. J Aging Phys Act 2017;25(4):653-670.

27. Cebrià i Iranzo MD, Arnall DA, Igual Camacho C, Tomas JM. Effects of inspiratory muscle training and yoga breathing exercises on respiratory muscle function in institutionalized frail older adults: a randomized controlled trial. J Geriatr Phys Ther 2014;37(2):65-75.

28. Reychler G, Delacroix S, Dresse D, Pieters T, Liistro G. Randomized controlled trial of the effect of inspiratory muscle training and incentive spirometry on respiratory muscle strength, chest wall expansion, and lung function in elderly adults. J Am Geriatr Soc 2016; 64(5):1128-1130.

29. McConnell A. Treinamento respiratório para um desempenho superior. Barueri, Spain: Manole; 2013:79-92. 


\section{InSPIRATORY Muscle Training IN Older Adults}

30. Kamen G. Aging, resistance training, and motor unit discharge behavior. Can J Appl Physiol 2005;30(3):341-351.

31. American Thoracic Society/European Respiratory Society. ATS/ERS statement on respiratory muscle testing. Am J Respir Crit Care Med 2002;166(4):518-624.

32. Meyer FJ, Borst MM, Zugck C, Kirschke A, Schellberg D, Kübler W, Haass M. Respiratory muscle dysfunction in congestive heart failure: clinical correlation and prognostic significance. Circulation 2001;103(17):2153-2158.

33. Pereira JLF, Galant LH, Rossi D, Telles da Rosa LH, Garcia E, de Mello Brandão AB, Marroni CA. Functional capacity, respiratory muscle strength, and oxygen consumption predict mortality in patients with cirrhosis. Can J Gastroenterol Hepatol 2016;2016:6940374.

34. Giua R, Pedone C, Scarlata S, Carrozzo I, Rossi FF, Valiani V, Incalzi RA. Relationship between respiratory muscle strength and physical performance in elderly hospitalized patients. Rejuvenation Res 2014;17(4):366-371.

35. Watsford ML, Murphy AJ, Pine MJ. The effects of ageing on respiratory muscle function and performance in older adults. J Sci Med Sport 2007;10(1):6-44.

36. van der Palen J, Rea TD, Manolio TA, Lumley T, Newman AB, Tracy RP, et al. Respiratory muscle strength and the risk of incident cardiovascular events. Thorax 2004;59(12):1063-1067.

37. Leith DE, Bradley M. Ventilatory muscle strength and endurance training. J Appl Physiol 1976;41(4):508-516.

38. American College of Sports Medicine. American College of Sports Medicine position stand. Progression models in resistance training for healthy adults. Med Sci Sports Exerc 2009;41(3):687-708.

39. Enright SJ, Unnithan VB. Effect of inspiratory muscle training intensities on pulmonary function and work capacity in people who are healthy: a randomized controlled trial. Phys Ther 2011;91(6):894-905.

40. Enright SJ, Unnithan VB, Heward C, Withnall L, Davies DH. Effect of high-intensity inspiratory muscle training on lung volumes, diaphragm thickness, and exercise capacity in subjects who are healthy. Phys Ther 2006;86(3):345-354.

41. Enright S, Chatham K, Ionescu AA, Unnithan VB, Shale DJ. Inspiratory muscle training improves lung function and exercise capacity in adults with cystic fibrosis. Chest 2004;126(2):405-411.
42. Cahalin LP, Arena R, Guazzi M, Myers J, Cipriano G, Chiappa G, et al. Inspiratory muscle training in heart disease and heart failure: a review of the literature with a focus on method of training and outcomes. Expert Rev Cardiovasc Ther 2013;11(2):161-177.

43. Zeren M, Demir R, Yigit Z, Gurses HN. Effects of inspiratory muscle training on pulmonary function, respiratory muscle strength and functional capacity in patients with atrial fibrillation: a randomized controlled trial. Clin Rehabil 2016;30(12):1165-1174.

44. Gomes Neto M, Martinez BP, Reis HF, Carvalho VO. Pre- and postoperative inspiratory muscle training in patients undergoing cardiac surgery: systematic review and meta-analysis. Clin Rehabil 2017; 31(4):454-464

45. Karadallı MN, Boşnak-Güçlü M, Camcıoğlu B, Kokturk N, Türktaş H. Effects of inspiratory muscle training in subjects with sarcoidosis: a randomized controlled Clinical Trial. Respir Care 2016;61(4):483494

46. Witt JD, Guenette JA, Rupert JL, McKenzie DC, Sheel AW. Inspiratory muscle training attenuates the human respiratory muscle metaboreflex. J Physiol 2007;584(3):1019-1028.

47. Almeida LB, Seixas MB, Trevizan PF, Laterza MC, Silva LP, Martinez DG. Effects of inspiratory muscle training on autonomic control: systematic review. Fisioter Pesqui 2018;25(3):345-351.

48. de Abreu RM, Rehder-Santos P, Minatel V, dos Santos GL, Catai AM. Effects of inspiratory muscle training on cardiovascular autonomic control: a systematic review. Auton Neurosci 2017;208: 29-35.

49. Wu J, Kuang L, Fu L. Effects of inspiratory muscle training in chronic heart failure patients: a systematic review and meta-analysis. Congenit Heart Dis 2018;13(2):194-202.

50. Geddes EL, O'Brien K, Reid WD, Brooks D, Crowe J. Inspiratory muscle training in adults with chronic obstructive pulmonary disease: an update of a systematic review. Respir Med 2008;102(12): 1715-1729.

51. Martín-Valero R, De La Casa Almeida M, Casuso-Holgado MJ, Heredia-Madrazo A. Systematic review of inspiratory muscle training after cerebrovascular accident. Respir Care 2015;60(11):16521659 . 